\title{
The Effect of Smartwork Environment on Organizational Commitment and Innovative Behavior in the Global Financial Service Industry
}

\author{
Myong Ok Kim*, Sooyeon Shin" \\ Department of International Office Administration, Ewha Womans University, Seoul, Republic of Korea \\ Email: "
}

Received 18 January 2015; accepted 13 February 2015; published 16 February 2015

Copyright (C) 2015 by authors and Scientific Research Publishing Inc.

This work is licensed under the Creative Commons Attribution International License (CC BY).

http://creativecommons.org/licenses/by/4.0/

(c) (i) Open Access

\begin{abstract}
This study analyzed how smartwork environment perceived by employees in global financial service industry (GFSI) influences their organizational commitment and innovative behavior. Data were collected through a questionnaire survey from 147 respondents randomly selected from seven global financial service firms in Seoul, Korea, where all three types of smartwork setting (working at home, mobile office, and smartwork center) are utilized. We found that no specific characteristic of smartwork environment (presenteeism, IT complexity, security risks, task interdependence) was significantly related to organizational commitment. For innovative behavior, only IT complexity and security risks of smartwork environment appeared to be significantly related. Contrary to our expectations, it was found that the negative emotion and stress of employees as to the complexity of IC technology and IT security risks can actually inspire their innovative behavior.
\end{abstract}

\section{Keywords}

Smartwork Environment, Organizational Commitment, Innvovative Behavior, Global Financial Service Industry

\section{Introduction}

Corporate competitiveness depends on implementing information system capable of rapidly responding to

"Corresponding author.

"Gradute.

How to cite this paper: Kim, M.O. and Shin, S. (2015) The Effect of Smartwork Environment on Organizational Commitment and Innovative Behavior in the Global Financial Service Industry. Journal of Service Science and Management, 8, 115-124. http://dx.doi.org/10.4236/issm.2015.81014 
Changes in the fast-paced business environment. The recent advent of smartphones and tablet PCs has catalyzed the changes in personal lifestyles and work environments. Prevalence of wireless and LTE technology has further accelerated such changes to the extent that people can easily work communicating with co-workers without temporal and spatial barriers.

In early 1999, RIM (Research in Motion) in Canada launched the Blackberry phone by incorporating a keyboard into a mobile phone, which enabled users to immediately view email messages, automatically transmitted to their phones from their email servers, anytime and anywhere [1]. Shortly, Blackberry phones proved successful in the financial service industry enough to be called a symbol of bankers on Wall Street and rapidly spread among those who engaged in financial services across the world.

At present, global financial service industry (GFSI) systematically makes use of IT systems, forming the smartwork environment for the benefit of collaboration, transcending the limits of time and space. Due to the characteristics of the smartwork environment, employees in GFSI can easily access their tasks via mobile devices at home. However, they become exposed to work excessively (work during their off-duty hours, after work, on weekends and on holidays, etc.) and in addition, actively participate in various events or organizational trainings [2]. The first objective of this study is to investigate whether GFSI employees' such voluntary participation in organizational activities and work without temporal and spatial limit is attributable to genuine organizational commitment from their inherent attachment to organizations. Competitiveness relies on fast preemptive actions in response to the changes in the fast-paced GFSI. With the advancement of smartwork environment, employees in foreign financial firms have come to exchange feedback in real time. In this context, the second objective of this study is to investigate whether new ideas are adopted and applied to organizations which induce innovative acts in favor of organization profit generation, given the smartwork environment is clearly conducive to conceiving such new ideas.

\section{Literature Review and Hypotheses}

\subsection{Smartwork Environment}

As workers' personal values and the types of tasks they do vary, the demand for work-life balance has increased. In the same vein, the rising demand for free hours and flexible working among workers and evolving network technologies have given birth to a new type of work setting, that is, the smartwork environment. Smartwork environment is a neologism where ICT (Information and Communication Technology) converges with the established concepts such as working at home, teleworking and flexible working, pursuing improvement of productivity and quality of life [3].

In this study the smartwork environment is defined as a type of work setting which uses diverse ICT and computing infra to collaborate and carry out tasks without temporal and distance restraints. Specifically, smartwork environment refers to the environment encompassing the three types of work setting, mobile office, home office, and smartwork center. Also, smartwork environment is characterized by four factors: presenteeism, attending and/or being exposed to work through ubiquitous accessibility and network [4]; IT complexity, causing users to learn and use up-to-date information technology [4]; security risks, leading to uneasiness concerning IT security and exposure of personal information and work [5]; and task interdependence, deriving from fast-paced business collaboration among co-workers [6]. Some researchers [7] said that what workers perceive from smartwork environment might vary considerably according to demographic factors such as gender, marital status, age, education, and the length of service (experience). Based on the literature review, this study proposes the hypotheses:

H1-1: Workers' perceptions of smartwork environment in GFSI are different by gender.

H1-2: Workers' perceptions of smartwork environment in GFSI are different by age.

H1-3: Workers' perceptions of smartwork environment in GFSI are different by work experience.

H1-4: Workers' perceptions of smartwork environment in GFSI are different by position.

\subsection{Smartwork Environment and Organizational Commitment}

Most scholars support the view of Meyer and Allen [8] who emphasized that organizational commitment reflects the psychological status between workers and organizations. Workers' attitudes and intentions of voluntary behavior, regardless of reward, emotional attachment to, identification with, and involvement in the organization reflect organizational commitment. In this study organizational commitment is defined as the degree to which 
workers devote themselves to offering their best practices in their teams and organizations [8].

The key to the success of today's business environment is cooperation using information technologies. Collaboration environment through ICT enables workers to work depending on the autonomous choice of working hours and places, so they strengthen a psychological investment in organizations, and this can increase not only effort for work but also emotional engagement in and commitment to organizations [9]. In teleworking environment sharing organization's goals among team members and exchanging and suggesting various opinions for achieving those goals positively affect the organizational growth. Trust, cooperation and respect for each other through these activities give a motive for organizational commitment and bring positive changes to work attitude and behavior [10].

At present, GFSI in Seoul, Korea is well equipped with smartwork technology. In smartwork environment integrating diverse information technologies at maximum, GFSI workers perform tasks cooperatively without temporal and spatial restrictions. Since mobile devices and teleworking system have been actively used in GFSI to overcome temporal and spatial restrictions, IT complexity causes workers inconvenience in keeping up their up-to-date information technology [4], and security risks associated with high technology become major source of stress for workers in GFSI. GFSI workers adjust the working hours and places autonomously, and this may increase the overall output but could promote the degree of task interdependence. Staples and Jarvenpaa [11] said that the more workers depend on one another, the more the tendency for information sharing increased, and the more the use of internal organization resources improved. Also, Pillari and Williams [12] said that groups with stronger coherence could promote good communication, group members could be committed to the organization through mutual evaluations and provide an opportunity for effective organization management.

However, as the dependence on information technologies and ubiquitous accessibility increase, presenteeism becomes conspicuous among workers, and they feel more that their privacy is invaded [5]. There exist many definitions on the term presenteeism in the literature. Presenteeism is variously portrayed as good (attending work, exhibiting excellent attendance), somewhat obsessive (working elevated hours, being reluctant to work part time rather than full time), at odds with one's health status (being unhealthy but exhibiting no sickness absenteeism, going to work despite feeling unhealthy), and often less than fully productive (reduced productivity at work due to health problems) [13]-[15]. In this study presenteeism is defined as being exposed to work by accessibility given through ICT. ICT with no temporal and spatial restrictions might hinder private time, and workers are constantly forced by the inside and outside of the organization to deal with the flow of information. They are also forced to perform tasks more quickly to meet the demand for information processing which is more rapidly increasing [4]. This role overload frequently occurs in GFSI. With almost no temporal and spatial restrictions due to the smartwork technology, all workers in GFSI are virtually to be available almost 24 hours a day for fast global business handling.

Although smartwork environment seems to bring a positive result to organizations by improving information sharing and cooperation of workers engaged in GFSI, there has been no research on whether GFSI workers in smartwork environment were truly committed to organizations from the bottom of their hearts. That discussion leads to the following hypotheses:

H2-1. Presenteeism of smartwork environment in GFSI has a significant effect on organizational commitment.

H2-2. IT complexity of smartwork environment in GFSI has a significant effect on organizational commitment.

H2-3. Security risks of smartwork environment in GFSI have a significant effect on organizational commitment.

H2-4. Task interdependence of smartwork environment in GFSI has a significant effect on organizational commitment.

\subsection{Smartwork Environment and Innovative Behavior}

Innovative behavior of employees is defined as the creation, introduction, and application of new ideas to organizational benefit and growth [16] [17]. Although several definitions of innovative behavior exist, the authors argue that during a process of innovation employees can show three aspects of individual innovative behavior: creativity, task revision, and persistence. Employees develop and express new and creative ideas, employees recognize deficits and revise their given task in order to improve it and feel competent about actually being able to propose changes, and employees persistently work on implementing the innovation without being discou- 
raged. There is a growing interest among scholars trying to answer the question why and under which circumstances employees actually get involved in innovative behavior at work [18]-[20].

Earlier researches of innovative behavior were focused on the discussion of personal creativity. However, creativity is one part of innovative behavior which helps the exercise of innovative behavior [21]. Encouraging employees transform their creativity into practical innovative behavior has become a popular issue in recent years [18]. If employees can effectively exercise their innovative behavior, it will help their enterprises stand out of complicated global business environment.

Creativity is considered as an important resource of GFSI. At present, not only GFSI in smartwork environment expects its employees to be highly creative in various ways in handling tasks, but also employees themselves make the hardest effort ever to upgrade their sense of creativity in order to survive in global financial business today. In particular, the fast-paced communication atmosphere of the GFSI in smartwork environment has accelerated workers sharing their views and ideas freely and exchanging feedback with peers all around the world in real time. Even though it is quite certain that such communication among workers of GFSI all over the world induces higher degree of creativity and cooperation, a conflict would be rather incited when there is a clash of opinions. It is not fully understood whether high degree of personal creativity shown by employees of GFSI is truly being transformed into adequate level of innovative behavior in smartwork environment which is characterized by presenteeism, IT complesity, security risks, and task interdependence. This contributes to the research motive of this study. Accordingly, the following hypotheses are constructed, and the overall research model is presented in Figure 1.

H3-1. Presenteeism of smartwork environment in GFSI has a significant effect on innovative behavior.

H3-2. IT complexity of smartwork environment in GFSI has a significant effect on innovative behavior.

H3-3. Security risks of smartwork environment in GFSI has a significant effect on innovative behavior.

H3-4. Task interdependence of smartwork environment in GFSI has a significant effect on innovative behavior.

\section{Methodology}

\subsection{Sample and Procedure}

The survey was conducted with employees in seven global financial service firms in Seoul, Korea, equipped with all of the three types of smartwork setting, working at home, mobile office, and smartwork center. At first, a pool of employees of GFSI was formed, who had all accesses to three types of smartwork setting (working at home, mobile office, smartwork center), and then the survey included randomly selected 147 respondents from the pool of employees. Respondents' answers were treated with utmost confidence.

Data collection was done by both online and offline questionnaire survey. Employees received an email with a link to the questionnaire. Respondents had a week time to fill out the questionnaires. The introduction letter of the questionnaire included supplementary information to motivate and inform the respondent about the survey. The descriptive analysis of respondents is given in Table 1.

\subsection{Measurements}

A questionnaire was first designed by the authors, adapting questions from previous studies, and then it was reviewed by a panel of five professionals including two faculty members, two analysts, and one personnel manager.

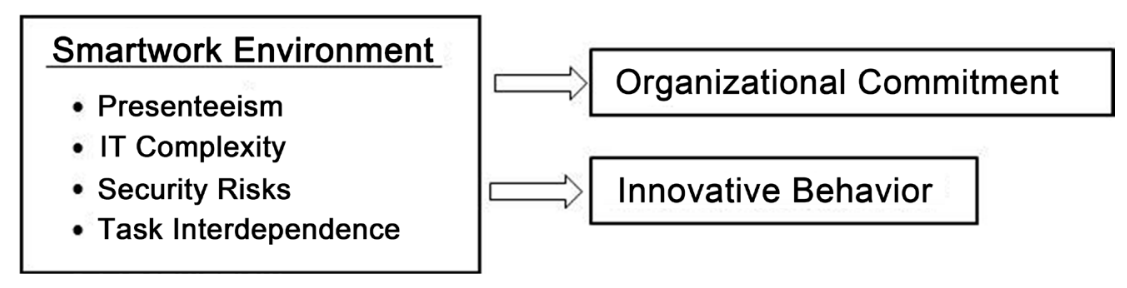

Figure 1. Research model: Effect of employees' perception of smartwork environment on organizational commitment and innovative behavior. 
Table 1. Descriptive analysis of respondents.

\begin{tabular}{cccc}
\hline & Classification & Frequency & \% of Frequency \\
\hline \multirow{2}{*}{ Gender } & Male & 82 & 56 \\
& Female & 65 & 44 \\
& $20-29$ & 81 & 55 \\
Age & $30-39$ & 50 & 34 \\
& $40-49$ & 13 & 2 \\
Experience & 50 or Older & 3 & 44 \\
& $<3$ Years & 64 & 29 \\
& 3 - 5 & 42 & 27 \\
Position & Analyst & 41 & 44 \\
& Associate & 64 & 40 \\
& Vice President & 59 & 11 \\
& Managing Director & 16 & 5
\end{tabular}

Characteristics of smartwork environment was measured with 24 questions (six questions for presenteeism [22] [23], six questions for IT complexity [22] [23], seven questions for security risks [5] [23], and five questions for task interdependence [6]). Sample questions are "ICTs enable me to access others" (presenteeism), "Learning to use ICTs is easy for me" (IT complexity), "Job processing using mobile office technology is not safe" (security risks), and "Cooperation with other employees is fast and easy through ICTs" (task interdependence). Organizational commitment was measured with six questions [24]. Sample question is "I am willing to put in considerable effort, beyond expectations, in order to help the organization be successful". Innovative behavior was measured with six questions [25]. Sample question is "I translate innovative ideas into feasible applications". All questions of the scale vary from 1 (completely disagree) to 5 (completely agree).

The scale for independent variable smartwork environment was found reliable (presenteeism, Cronbach's $\alpha=$ 0.868 ; IT complexity, Cronbach's $\alpha=0.864$; security risks, Cronbach's $\alpha=0.883$; task interdependence, Cronbach's $\alpha=0.808$ ). The scale for dependent variable organizational commitment was found reliable (Cronbach's $\alpha=0.849$ ), and the scale for dependent variable innovative behavior was found reliable (Cronbach's $\alpha=0.861$ ).

Validity check for the whole scale was conducted by exploratory factor analysis. All items of the dependent and independent variables were submitted to a principal components analysis with Varimax orthogonal rotation. As a result, six factors (smartwork environment with four characteristics, organizational commitment, and innovative behavior) were identified with an eigenvalue greater than 1, accounting for 60.2 percent of the variance. Each item loaded on its appropriate factor, with primary loadings exceeding 0.40 .

\section{Results}

\subsection{Correlation Analysis}

Table 2 shows means, standard deviations, and Pearson correlations among all variables. Innovative behavior is negatively related to IT complexity $(r=-0.432, \mathrm{p}<0.01)$ and positively related to security risks $(\mathrm{r}=0.350, \mathrm{p}<$ $0.05)$ and organizational commitment $(r=0.517, \mathrm{p}<0.01)$. Presenteeism is positively related to IT complexity $(\mathrm{r}$ $=0.694, \mathrm{p}<0.01)$ and task interdependence $(\mathrm{r}=0.537, \mathrm{p}<0.01)$. IT complexity is negatively related to security risks $(r=-0.160, p<0.05)$. Smartwork environment is not significantly related to organizational commitment.

\subsection{Demographic Traits and Smartwork Environment}

T-test and one-way ANOVA methods were used to find out any difference in the perception of smartwork environment among employees in GFSI in Seoul in line with demographic traits (gender, age, experience, and position). Equal variance assumption was validated with the significance levels of $\mathrm{F}$ values of all small group analyses for four demographic lines being greater than 0.05 , except two following cases. 
Table 2. Pearson correlations among the variables.

\begin{tabular}{ccccccccc}
\hline Variable & M & SD & 1 & 2 & 3 & 4 & 5 & 6 \\
\hline 1. Presenteeism & 3.74 & 0.57 & 1 & & & & & \\
2. IT Complexity & 3.68 & 0.61 & $0.694^{* *}$ & 1 & & & & \\
3. Security Risks & 3.15 & 0.52 & -0.211 & $-0.160^{*}$ & 1 & & & \\
4. Task Interdependence & 3.75 & 0.50 & $0.537^{* *}$ & 0.243 & 0.060 & 1 & & \\
5. Organizational Commitment & 3.25 & 0.84 & 0.044 & -0.003 & -0.014 & 0.158 & 1 & $0.517^{* *}$ \\
6. Innovative Behavior & 3.41 & 0.72 & 0.138 & $-0.432^{* *}$ & $0.350^{*}$ & -0.246 & 1 \\
\hline
\end{tabular}

${ }^{*} \mathrm{p}<0.05 ;{ }^{* *} \mathrm{p}<0.01$.

The difference in the perception of security risks of smartwork environment caused by gender was proved to be significant (security risks: $t=-2.070, p=0.040, \alpha=0.05$ ). Female employees perceived security risks caused by smartwork environment more seriously than male employees (female mean $=3.28$, male mean $=3.04$ ). Hence, hypothesis H1-1 was partially supported. Also, the difference in the perception of presenteeism of smartwork environment caused by work experience was proved to be significant (presenteeism: $\mathrm{F}=3.626, \mathrm{p}=0.008, \alpha=$ 0.05). More specifically by additional Scheffépost hoc test, difference between the group with 3 to 5 years of work experience (mean $=3.81$ ) and the group with 5 years or longer (mean $=2.98$ ) was proved to be significant. The group of 3 to 5 years of work experience felt more presenteeism than the group of 5 years or longer work experience. In all other group comparisons, no significant difference was found. Hence, hypothesis H1-3 was partially supported. Hypotheses H1-2 and H1-4 were not confirmed.

\subsection{Regression Analyses}

The results of the regression analysis to test the hypotheses H2 groups are presented in Table 3. The influence of smartwork environment (all four factors) on organizational commitment of workers in GFSI in Seoul was not found to be significant. Hence, hypotheses H2-1, H2-2, H2-3, and H2-4 were not confirmed.

The results of the regression analysis to test the hypotheses H3 groups are presented in Table 4. The influence of the two factors, IT complexity $(\beta=0.412, \mathrm{p}<0.01)$ and security risks $(\beta=0.200$, $\mathrm{p}<0.01)$ of smartwork environment on innovative behavior of workers in GFSI in Seoul was found to be significant. As shown in Table 4, IT complexity and security risks together could explain $26 \%$ of dependent variable innovative behavior $(\mathrm{F}=$ 12.190, $\mathrm{p}<0.01$ ), and IT complexity showed stronger influence on innovative behavior than security risks. Also, diagnosis for multicollinearity was performed, and the result (Durbin-Watson $=1.884$, all VIFs close to 1 ) indicated that the regression model for dependent variable innovative behavior was appropriate. Hence, hypotheses H3-2 and H3-3 were supported. Hypotheses H3-1 and H3-4 were not confirmed.

\section{Discussions}

The objective of this study was to answer the question whether the smartwork environment perceived by employees influences their organizational commitment and innovative behavior. To clarify these relationships we used data from employees working in global financial service industry in Seoul, Korea. The findings of this study are as follows.

First, there were significant differences in employees' awareness of smartwork environment depending on their gender and work experiences. Female employees were more aware of and concerned about security risks than male employees. It is suggested to take this finding into consideration when in-house IT and smartwork technology training program is planned in GFSI. Also, the group with 3 - 5 years of work experience showed the highest awareness of presenteeism. Groups with the most work experience (5 years or more) recognized presenteeism at much lower level than the middle experience group ( 3 - 5 years of work experience). It has been observed that GFSI has wider variation in terms of working hours and the scope and amount of tasks and requires faster job processing time than any other industry. Especially, the middle experience group of employees in GFSI have to carry out the most intensive and extensive amount of tasks, and they also have the highest workloads among all groups as they ought to face promotion battle from analysts to associate position. It might be advantageous for both company and employees in the long run that this finding is considered when tasks are reorganized to enhance overall productivity, to draw attention equally of all experience groups to presenteeism in smartwork environment in GFSI. 
Table 3. Result of regression analysis for WLB and organizational commitment.

\begin{tabular}{|c|c|c|c|c|c|}
\hline \multirow{2}{*}{$\begin{array}{l}\text { Independent } \\
\text { Variable }\end{array}$} & Standardized Regression Coefficients & \multirow{2}{*}{$\mathrm{t}$} & \multirow{2}{*}{ Sig. } & \multicolumn{2}{|c|}{ Multicollinearity } \\
\hline & $\beta$ & & & Tolerance & VIF \\
\hline (Constant) & & 7.079 & 0.000 & & \\
\hline Presenteeism & 0.164 & 1.626 & 0.106 & 0.676 & 1.480 \\
\hline IT Complexity & 0.043 & 0.385 & 0.701 & 0.548 & 1.824 \\
\hline Security Risks & -0.010 & -0.121 & 0.904 & 0.940 & 1.063 \\
\hline Task Interdependence & -0.058 & -0.564 & 0.574 & 0.650 & 1.538 \\
\hline $\mathrm{R}^{2}=0.029$ & Sig. $=0.371$ & & Dubin- & on $=1.475$ & \\
\hline
\end{tabular}

${ }^{* *} \mathrm{p}<0.01$.

Table 4. Result of regression analysis for WLB and innovative behavior.

\begin{tabular}{|c|c|c|c|c|c|}
\hline \multirow{2}{*}{$\begin{array}{l}\text { Independent } \\
\text { Variable }\end{array}$} & \multirow{2}{*}{$\begin{array}{c}\text { Standardized Regression Coefficients } \\
\beta\end{array}$} & \multirow{2}{*}{$\mathrm{t}$} & \multirow{2}{*}{ Sig. } & \multicolumn{2}{|c|}{ Multicollinearity } \\
\hline & & & & Tolerance & VIF \\
\hline (Constant) & & 2.443 & 0.016 & & \\
\hline Presenteeism & 0.075 & 0.851 & 0.396 & 0.676 & 1.480 \\
\hline IT Complexity & $0.412^{* *}$ & 4.211 & 0.000 & 0.548 & 1.824 \\
\hline Security Risks & $0.200^{* *}$ & 2.681 & 0.008 & 0.940 & 1.063 \\
\hline Task Interdependence & 0.013 & 0.149 & 0.882 & 0.650 & 1.538 \\
\hline $\mathrm{R}^{2}=0.256$ & Sig. $=0.000$ & & Dubin-W & $\mathrm{n}=1.884$ & \\
\hline
\end{tabular}

${ }^{* *} \mathrm{p}<0.01$.

Secondly, it has been found that the smartwork environment perceived by employees in GFSI did not affect their organizational commitment. Here, it is worth noticing that any of four factors (presenteeism, IT complexity, security risks, and task interdependence) of smartwork environment had no meaningful effect on organizational commitment; i.e., regardless of their busy life anywhere anytime, employees in smartwork environment in GFSI neither emotionally engage themselves in nor truly commit to organizations from the bottom of their hearts. It can be easily seen that employees handle tasks without temporal and spatial restrictions using IC technology, or the time and effort devoted to their tasks get increased, etc. in smartwork environment in GFSI; however, it is verified that such phenomena are not significantly related to truly voluntary commitment. The core of the smartwork environment is the connectivity supported by computerized systems and communication technology. It has allowed employees to share information and resources as well as carry out various task processes in cooperation. Jeong [26] found that in general business environment ICT enables employees to share opinions and feedback, such activities cultivate their mutual trust, cooperation, and respect, and as a result their organizational commitment increases, which positively affects their job attitude and behavior. However, in this study we obtained the opposite results for employees in smartwork environment of GFSI. Although the smartwork environment seems to inspire the collaboration of the employees and positively affect their performance, it turned out to beirrelevant to their organizational commitments. It is suggested that GFSI in smartwork environment not only emphasizes enhancement of the productivity but also take employees’ internal psychological state, i.e., emotional attachment to, identification with, and involvement in the organization into consideration. It is strongly recommended for the company to pay attention to not only performance at work but also work-life balance of employees and to support them to achieve and maintain the quality of life.

Thirdly, IT complexity perceived by employees in smartwork environment in GFSI significantly affected their innovative behavior. Unlike creativity that focuses on generating new ideas, innovative behavior includes accepting and using new ideas for specific problem solving at work. It may be easily guessed that the stress and a psychological burden caused by acquiring new information technology might have a negative impact on innovative behavior of employees. However, this study found that the negative emotions of employees as to the complexity of information and communication technology can actually inspire their innovative behavior. This result agrees with a previous research finding [19] saying that employees demonstrate their innovative behavior 
when they encounter difficulties and obstacles at work.

Fourthly, the security risks of smartwork environment had a significant impact on innovative behavior of employees. Kim [27] has found that IT security concerns of employees in smartphone-based mobile office in general business areas lead to lower intention of accepting IT devices. However, in this study we have investigated employees in smartwork environment in GFSI, and the finding is quite different from that of the previous research [27]. Despite their anxiety over security risks, employees in smartwork environment in GFSI seem to rather face the problem and make every possible effort to overcome it. Also, employees' freedom to suggest and the atmosphere of encouraging new ideas, amid the horizontal organizational culture, seem to inspire their innovative behavior; it leads to their organizational development. Thus, it is recommended for GFSI not only be very aggressive in introducing high smartwork technology to their employees, but also at the same time to ease them of security anxiety by providing them more secure IT environment for work and/or providing them wider open channel for communication over IT security anxiety.

Fifthly, the presenteeism perceived by employees in smartwork environment in GFSI has no significant effect on their innovative behavior. Since employees were aware of that they could exercise autonomy and flexibility to complete their tasks, it was assumed that they would make various task-related attempts, and their innovative behavior could be positively affected by that. However, in this study the opposite result was found. Since employees are constantly forced to perform tasks more and better with no temporal and spatial restrictions, the quantity of work produced might be greatly noticeable on the surface. It has been verified that this role overload which occurs frequently in smartwork environment in GFSI became obstacle to innovative behavior. Thus, it is strongly suggested for GFSI to make a compromise between quantity of outcome and quality of life and internal satisfaction of employees. By converting its direction from presenteeism to work-life balance, GFSI could have a good harvest in the long run.

Sixthly, the task interdependence of smartwork environment perceived by employees of GFSI is irrelevant to their innovative behavior. The ultimate purpose of smartwork environment is to encourage the collaboration of employees. Creating new, useful ideas is often accomplished through the cooperative efforts of employees and their positive relationships [28]. The impact of task-related interdependence of employees on their innovative behavior is expected to become positive. However, we discovered that the task interdependence in smartwork environment in GFSI helps employees generate ideas and promote communication for better organizational performance, but, those efforts do not lead to their innovative behavior. It is worth seriously considering all possible means to elevate the effect of communicating and sharing ideas in real time and exchanging feedback among employees and to revamp organizational culture in smartwork environment in GFSI. Also, the organization should focus on the publicity and advocacy of organizational innovation culture and concept. In addition, the organization should utilize internal training, promotion, authorization, goal orientation so as to encourage employees' innovative behavior [29].

\section{Conclusion and Recommendations}

This study analyzed how smartwork environment perceived by employees in global financial service industry (GFSI) influences their organizational commitment and innovative behavior. Data were collected through a questionnaire survey from 147 respondents randomly selected from seven global financial service firms in Seoul, Korea, where all three types of smartwork setting (working at home, mobile office, and smartwork center) are utilized. We found that no specific characteristic of smartwork environment (presenteeism, IT complexity, security risks, task interdependence) was significantly related to organizational commitment. Regardless of their active voluntary business participation on the surface without temporal and spatial restrictions using IC technology, employees in smartwork environment in GFSI neither emotionally engage themselves in nor truly commit to organizations. For innovative behavior, only IT complexity and security risks of smartwork environment appeared to be significantly related. Contrary to our expectations, it was found that the negative emotion and stress of employees as to the complexity of IC technology and IT security risks can actually inspire their innovative behavior. These results fell short of our expectations with no small degree; employees' performance on the surface working in smartwork environment in GFSI did not represent in reality how they feel in their hearts toward their organization and work. Even though it is almost not possible to control or eliminate some problematic characteristics of smartwork environment in GFSI, it would be advantageous for both organization and employees if the results of this study were taken into consideration when overall effectiveness and productivity in the long run are examined. 
This study has some limitations. First, due to insufficient research time, the sample size of this study may not be large enough and adequate. This study collected data from 147 respondents randomly selected from seven global financial service firms in Seoul, Korea, where all three types of smartwork setting (working at home, mobile office, and smartwork center) are utilized. It is recommended that the future research consider larger sample for better representativeness and generalization. Second, future research could be extended but also deepened by a qualitative part to have a better understanding about working in smartwork environment and organizational commitment: collecting in-depth information on internal and psychological factors such as personal emotional affectivity (positive or negative, extroverted or introverted, active or passive, etc.) and the state of work-life balance of respondents, and further empirically testing them as moderating variables for more diverse results.

Strength of this study is that we focused on how working in smartwork environment in global financial service industry in Seoul, Korea is related to organizational commitment and innovative behavior. It appeared that no specific factor of working in smartwork environment (presenteeism, IT complexity, security risks, task interdependence) was significantly related with organizational commitment. For innovative behavior, only IT complexity and security risks of smartwork environment appeared to be significantly related. These results fell short of our expectations with no small degree; employees' performance on the surface working in smartwork environment in GFSI did not represent in reality how they feel in their hearts toward their organization and work. Even though it is almost not possible to control or eliminate some special problematic characteristics of smartwork environment in global financial service industry, it would be beneficial for both GFSI and workers if the results of this study were taken into consideration when overall productivity of the management system in GFSI is examined.

\section{References}

[1] ACROFAN (2013) Five Inventions Which Have Contributed to Global Workplace. http://www.acrofan.com/ko-kr/live/news/20131028/00000006

[2] Koo, S.H., Lee, J.E. and Shin, M.S. (2012) The Effect of Mobile Office Service Quality Factors on the User Satisfaction: Focused on Usage and Job Characteristics. Journal of Korea Society of IT Services, 11, 1-17.

http://dx.doi.org/10.9716/KITS.2012.11.2.001

[3] President's Council on Informatization Strategies (2011) A Research on Activation Model of Smartwork.

[4] Seo, A.Y. (2012) Factors Affecting Individuals’ Job Satisfaction in Smartwork Environment. The E-Business Studies, 13, 281-316.

[5] Lee, S.K. (2012) An Empirical Research on the Determinants of Job Stress of Employee for IT Security in Quasi Public Institutions: Focused on the Influence of Institutional, Technological, Cultural, Personal Factors on the Security Fatigue. Unpublished Dissertational Thesis, Korea University, Seoul.

[6] Kim, J.Y. (2011) A Study on the Relationship between Task Characteristics and the Use of Mobile Office Systems. Unpublished Dissertational Thesis, Hanyang University, Seoul.

[7] Joo, S.G., Son, Y.G. and Jeon, S.G. (2012) Policy Implications for the Smart Work Diffusion: Focusing on the Perceptual Differences on Organizational Effectiveness between Smart Workers and Office Workers. Journal of Digital Policy \& Management, 10, 11-22.

[8] Meyer, J.P. and Allen, N.J. (1991) A Three-Component Conceptualization of Organizational Commitment. Human Resources Management Review, 1, 61-89. http://dx.doi.org/10.1016/1053-4822(91)90011-Z

[9] Yang, J.S. (2011) The Effect of Relational Characteristics of Organizational Members on Job Performance in Collaboration Environment Using Information System. Unpublished Doctoral Dissertation, Chonnam National University, Kwangju.

[10] Yang, M.H. and Bae, J.K. (2009) A Study of Factors Affecting Attitude towards Teleworking: An Attitude Survey of KIPO (Korean Intellectual Property Office) Examiners. Journal of Korea Communication Association, 17, 97-123.

[11] Staples, D.S. and Jarvenpaa, S.L. (2000) The Use of Collaborative Electronic Media for Information Sharing: An Exploratory Study of Determinants. The Journal of Strategic Information Systems, 9, 129-154.

[12] Pillari, R. and Williams, E.A. (2004) Transformation Leadership, Self-Efficacy, Group Cohesiveness, Commitment and Performance. Journal of Organizational Change Management, 17, 212-231.

[13] Smith, D.J. (1970) Absenteeism and Presenteeism in Industry. Archives of Environmental Health, 21, 670-677. http://dx.doi.org/10.1080/00039896.1970.10667313

[14] Stolz, R.L. (1993) Reducing Turnover through Incentive Programs. Cornell Hotel and Restaurant Administration 
Quarterly, 34, 79-80.

[15] Johns, G. (2010) Presenteeism in the Workplace: A Review and Research Agenda. Journal of Organizational Behavior, 31, 519-542. http://dx.doi.org/10.1002/job.630

[16] Janssen, O. (2000) Job Demands, Perceptions of Effort-Reward Fairness and Innovative Work Behavior. Journal of Occupational and Organizational Psychology, 73, 287-302. http://dx.doi.org/10.1348/096317900167038

[17] Amabile, T. (1988) A Model of Creativity and Innovation in Organizations. In: Staw, B.M. and Cummings, L.L., Eds., Research in Organization Behavior, JAI Press, Greenwich, USA, 123-167.

[18] Ramamoorty, N., Flood, P.C., Slattery, T. and Sardessari, R. (2005) Determinants of Innovative Work Behavior: Development and Test of an Integrated Model. Creativity and Innovation Management, 14, 142-150. http://dx.doi.org/10.1111/j.1467-8691.2005.00334.x

[19] Kim, I.C., Kim, J.W. and Lee, J.W. (2004) Determinants of Innovative Work Behavior. Journal of Business Research, 19, 281-316.

[20] Janssen, O. (2003) Innovative Behavior and Job Involvement at the Price of Conflict and Less Satisfactory Relations with Co-Workers. Journal of Occupational and Organizational Psychology, 76, 347-364. http://dx.doi.org/10.1348/096317903769647210

[21] West, M.A. and Farr, J.L. (1989) Innovation at Work: Psychological Perspectives. Social Behavior, 4, 15-30.

[22] Ayyagari, R., Grover, V. and Purvis, R. (2011) Technostress: Technological Antecedents and Implications. Management Information System Quarterly, 35, 831-858.

[23] Choi, G.Y. (2011) A Study on the Influential Factors on the Job Stress for Mobile Office Users. Unpublished Dissertational Thesis, Yonsei University, Seoul.

[24] Lee, K., Allen, N.J., Meyer, J.P. and Rhee, K. (2001) The Three-Component Model of Organizational Commitment: An Application to South Korea. Applied Psychology, 50, 596-614. http://dx.doi.org/10.1111/1464-0597.00075

[25] Scott, S.G. and Bruce, R.A. (1994) Determinants of Innovative Behavior: A Path Model of Individual Innovation in the Workplace. Academy of Management Journal, 37, 580-607. http://dx.doi.org/10.2307/256701

[26] Jeong, K.H. (2010) The Effects of Perceived Interdependence of Information System Employees on Group Cohesiveness, Organizational Trust, and Organizational Commitment. Journal of KECRA, 11, 23-39.

[27] Kim, S.Y. (2013) A Study on the Acceptance Intention for Smart Phone Mobile Office: Using an Extended TAM. Unpublished Dissertational Thesis, Kunkuk University, Seoul.

[28] Park, K.K. and Lee, I.S. (2000) Corporate Globalization and New Paradigm for Management Process: Innovation as Attackers' Advantages. Journal of Korean Academy of Organization and Management, 24, 29-85.

[29] Li, X. and Zheng, Y. (2014) The Influential Factors of Employees' Innovative Behavior and the Management Advices. Journal of Service Science and Management, 7, 446-450. http://dx.doi.org/10.4236/jssm.2014.76042 
Scientific Research Publishing (SCIRP) is one of the largest Open Access journal publishers. It is currently publishing more than 200 open access, online, peer-reviewed journals covering a wide range of academic disciplines. SCIRP serves the worldwide academic communities and contributes to the progress and application of science with its publication.

Other selected journals from SCIRP are listed as below. Submit your manuscript to us via either submit@scirp.org or Online Submission Portal.
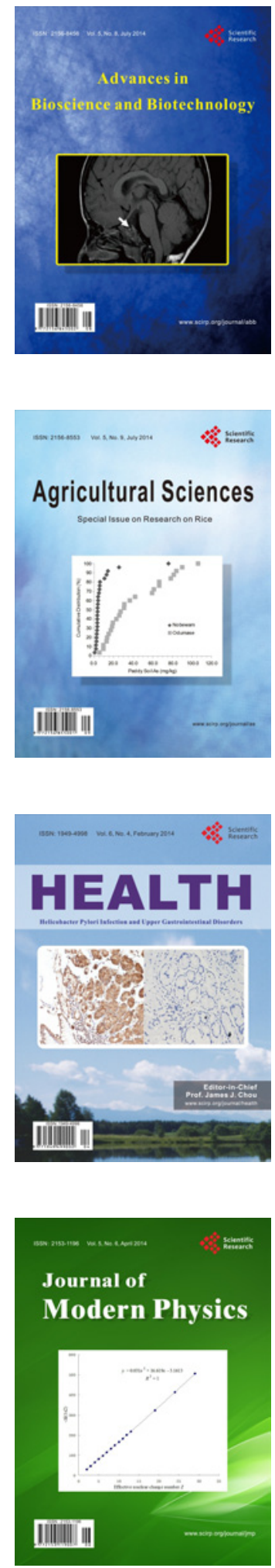
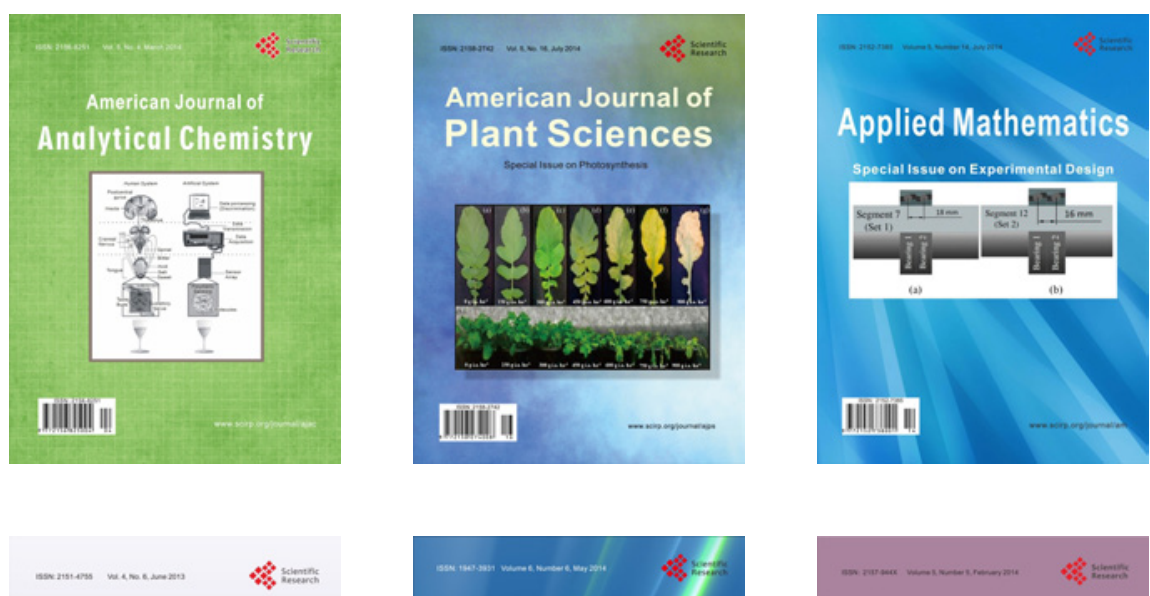

Creative Education
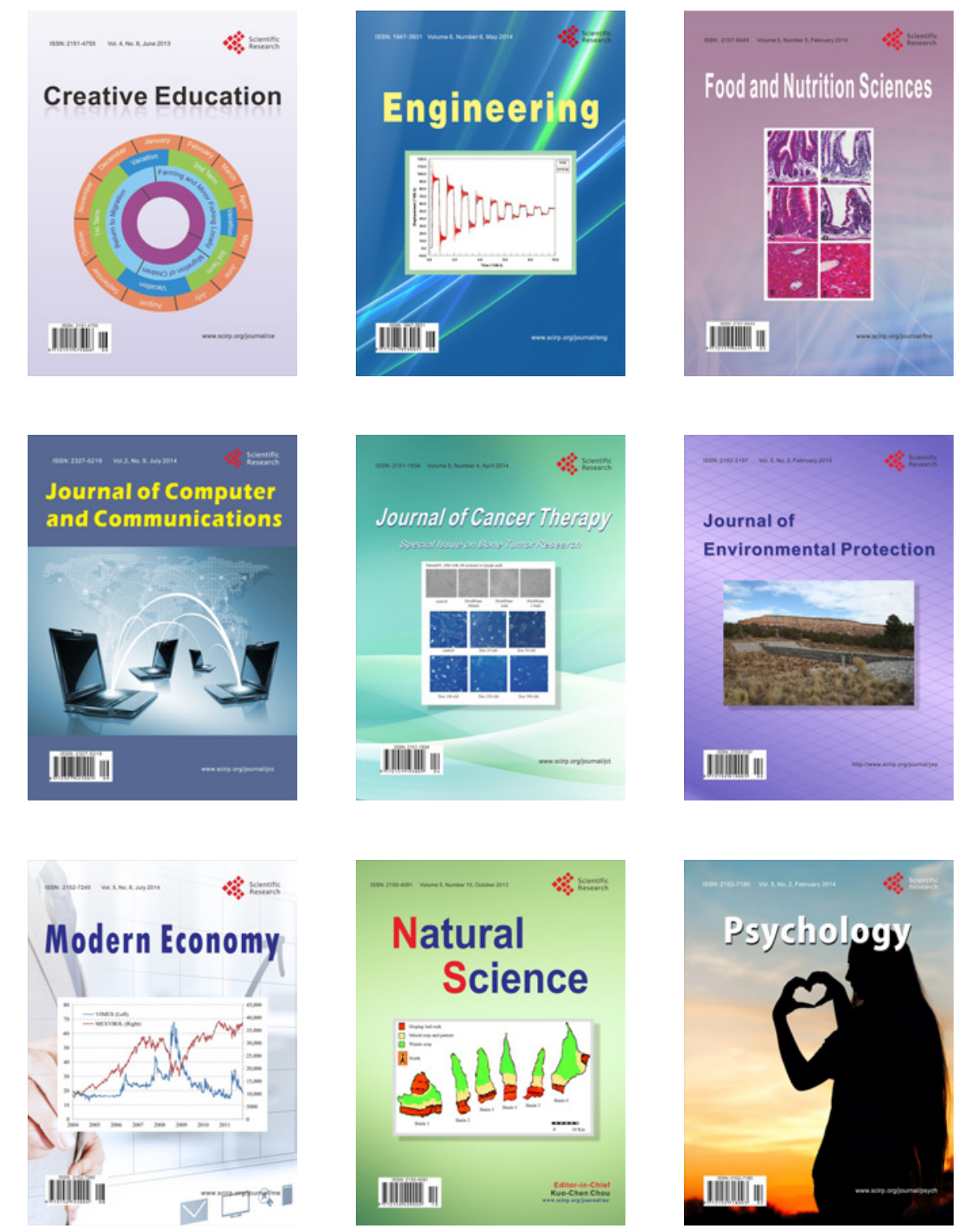